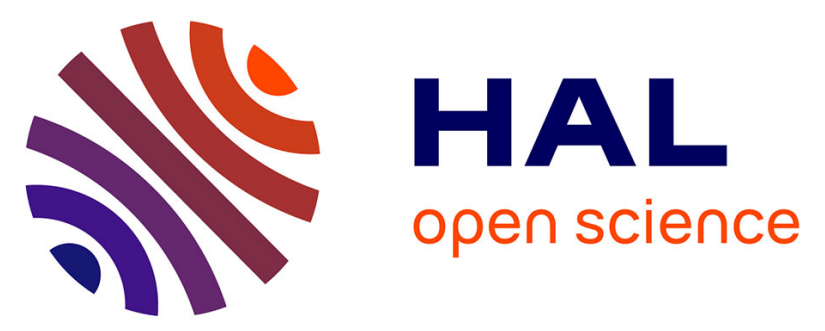

\title{
Improvement of the sensitivity for the measurement of copper concentrations in soil by microwave-assisted laser-induced breakdown spectroscopy
}

Yuan Liu, Bruno Bousquet, Matthieu Baudelet, Martin Richardson

\section{- To cite this version:}

Yuan Liu, Bruno Bousquet, Matthieu Baudelet, Martin Richardson. Improvement of the sensitivity for the measurement of copper concentrations in soil by microwave-assisted laser-induced breakdown spectroscopy. Spectrochimica Acta Part B: Atomic Spectroscopy, 2012, 73, pp.89-92. 10.1016/j.sab.2012.06.041 . hal-00732080

\section{HAL Id: hal-00732080 \\ https://hal.science/hal-00732080}

Submitted on 30 Aug 2018

HAL is a multi-disciplinary open access archive for the deposit and dissemination of scientific research documents, whether they are published or not. The documents may come from teaching and research institutions in France or abroad, or from public or private research centers.
L'archive ouverte pluridisciplinaire HAL, est destinée au dépôt et à la diffusion de documents scientifiques de niveau recherche, publiés ou non, émanant des établissements d'enseignement et de recherche français ou étrangers, des laboratoires publics ou privés.

\section{(1)(1) $\$(0)$}

Distributed under a Creative Commons Attribution - NonCommercial - ShareAlikel 4.0 


\title{
Improvement of the sensitivity for the measurement of copper concentrations in soil by microwave-assisted laser-induced breakdown spectroscopy
}

\author{
Yuan Liu ${ }^{a}$, Bruno Bousquet ${ }^{b, c}$, Matthieu Baudelet ${ }^{\mathrm{a}, *}$, Martin Richardson ${ }^{\text {a }}$ \\ a Townes Laser Institute, CREOL - The College of Optics and Photonics, University of Central Florida, 4000 Central Florida Boulevard, Orlando, FL 32816, USA \\ b Univ. Bordeaux, LOMA, UMR 5798, F-33400 Talence, France \\ c CNRS, LOMA, UMR 5798, F-33400 Talence, France
}

\section{A R T I C L E I N F O}

\section{Keywords:}

LIBS

Microwave-assisted LIBS

Copper

Soil

Sensitivity

\begin{abstract}
A B S T R A C T
This study shows a 23 fold improvement of the sensitivity in the determination of copper in soil samples when using Microwave Assisted Laser Induced Breakdown Spectroscopy (MA LIBS) compared with our conventional LIBS. This comparison between MA LIBS and LIBS was performed with identical ablation condi tions and detection geometry. The signal enhancement obtained with MA LIBS allowed for the detection of spectral lines related to concentration values as low as $30 \mathrm{mg} \mathrm{kg}^{-1}$ for copper and $23.3 \mathrm{mg} \mathrm{kg}^{-1}$ for silver, which were not detected by LIBS.
\end{abstract}

\section{Introduction}

The monitoring of concentration of metallic elements in soil is of great importance to environmental research, agriculture, and public health [1 3]. Mobile toxic metals in the soil $(\mathrm{Cu}, \mathrm{Pb}, \mathrm{Cd}, \mathrm{Cr}, \ldots)$ can accumulate in the human body through the food chain $[3,4]$ or prolonged exposure to trace amounts of contaminated aerosols [5]. The so called heavy metals in the soil, whether naturally concentrated or from the discharge of industrial or civilian waste, are harmful to the health of human beings, animals and plants. Overdose of metal salts $(\mathrm{Na}, \mathrm{Ca}$, and $\mathrm{Mg}$ ) in the soil results in salinization [1], which can reduce the productivity of farmland and have serious consequences on food production.

An element of interest is copper. The copper concentration in soil de termines if it should be considered as a nutrient for plants or a toxic me tallic pollutant. As a nutrient, copper is absorbed by plants and involved in photosynthesis and respiration [6]. However, a high concentration of copper can lead to growth reduction and other issues [7]. For human be ings, both copper deficiency and excess can cause health problems [8]. For ecological preservation, $61 \mathrm{mg} \mathrm{kg}^{-1}$ is set as the soil screening level (SSL) for copper by the Environmental Protection Agency (EPA), which is the level that triggers further ecological risk assessment [9].

Major environmental hazards can be contained or prevented by monitoring the elemental composition of the soil. With the data obtained, necessary warnings can be given and remedial action can be taken. Laser induced breakdown spectroscopy (LIBS) is a technique

\footnotetext{
* Corresponding author.

E-mail address: baudelet@creol.ucf.edu (M. Baudelet).
}

attracting increasing attention from both researchers and end users for environmental monitoring. In LIBS, focused laser radiation is used to ablate and excite the sample material simultaneously. The plasma created from the sample material provides elemental information about the sample via the optical emission $[10,11]$. Compared with sev eral elemental analysis methods for environmental monitoring such as X ray fluorescence, inductively coupled plasma mass spectrometry (ICP MS) or optical emission spectroscopy (ICP OES), and atomic ab sorption spectroscopy, LIBS can achieve multi element analysis with re duced time and labor costs, since no or minimal sample preparation is required [12]. With the development of lasers and improved detection techniques, LIBS has been applied to complex environmental samples such as soils and rocks in recent years for both qualitative and quantita tive analyses [13 18].

To measure the concentration of metals in soil, calibration curves are usually used. The slope of this curve defines the sensitivity of the analyt ical method according to the IUPAC definition [19]. Assuming similar precision, higher sensitivity would allow for better discrimination be tween two close values of concentration [20] and helps regulators to achieve conclusive and accurate decision making. Although LIBS has made progress towards applications in environmental analysis, its sensi tivity still needs to be improved compared to other standard techniques [12,21]. LIBS signal enhancement through microwave heating is a new method studied recently [22 24]. As reported in Ref. [22], the microwave plasma coupling extends the plasma emission lifetime to milliseconds, from tens of microseconds in conventional LIBS. As a conse quence, the line intensity can be strengthened several tens of times. This study presents the improvement of the sensitivity of LIBS for the deter mination of copper in soil samples using Microwave Assisted LIBS as 
Table 1

Concentration of $\mathrm{Cu}$ and major elements in soil samples referred to as S1-S4.

\begin{tabular}{lllll}
\hline & $\mathrm{Cu}\left(\mathrm{mg} \mathrm{kg}^{1}\right)$ & $\mathrm{Al}_{2} \mathrm{O}_{3}(\%)$ & $\mathrm{Fe}_{2} \mathrm{O}_{3}(\%)$ & $\mathrm{SiO}_{2}(\%)$ \\
\hline $\mathrm{S} 1$ & 1232 & 16.3 & 11 & 55.5 \\
$\mathrm{~S} 2$ & 738 & 12.4 & 6.8 & 60.3 \\
$\mathrm{~S} 3$ & 544 & 16.5 & 10.7 & 52.3 \\
$\mathrm{~S} 4$ & 30 & 11.2 & 6.5 & 68.9 \\
\hline
\end{tabular}

well as for the detection of silver and copper at concentrations not detected with our conventional LIBS system.

\section{Experimental}

\subsection{LIBS and MA LIBS}

The experimental setup of LIBS and MA LIBS was similar to the one in Ref. [22]. The nanosecond laser (Brilliant, Quantel), the micro wave system (Envimetrics), the spectrometer (2300i, Princeton Instruments Acton) and the ICCD camera (PIMAX, Princeton Instru ments) were used as the basic components of the LIBS and MA LIBS setups. The key differences between this study and Ref. [22] were the laser energy and focusing conditions, as well as the spectral acquisi tion parameters. Laser pulses with $10 \mathrm{~mJ}$ energy and 5 ns duration were focused inside the sample, forming a $160 \mu \mathrm{m}$ diameter spot on the sam ple surface. This spot size was optimized for the maximum LIBS signal and minimum signal fluctuation. For MA LIBS, the same ablation condi tion was used. The plasma emission was collected from the side by a UV transmissive fiber at about $70^{\circ}$ from the laser direction without ad ditional focusing lenses. The position of the fiber was optimized to ob tain the maximum LIBS signal. The gate delay was set at $500 \mathrm{~ns}$ to eliminate the initial continuum emission, and a $20 \mathrm{~ms}$ or a $10 \mu$ s gate width was applied respectively when the microwave generator was either activated or not. Each spectrum was obtained by adding ten accu mulations at the same spot, and 5 spectra from different locations were averaged to obtain the final spectra.

\subsection{Samples}

The four soil samples were a subset of the samples used in Ref. [18]. The copper concentrations, measured by ICP OES, were evaluated at
$1232,738,544$, and $30 \mathrm{mg} \mathrm{kg}^{-1}$ in order to measure the sensitivity over a wide range. In the following discussions the samples are labeled as S1 S4 with S1 having the highest concentration and S4 the lowest. These samples were natural soil samples from different locations rather than matrix matched soils made in the laboratory, considering a linear calibration curve may have been difficult to obtain due to matrix effects in the latter case $[17,18]$. In order to reduce these effects, the above sam ples were chosen to contain relatively similar concentrations of major elements like $\mathrm{Fe}, \mathrm{Si}$, and $\mathrm{Al}$ (Table 1). The soils samples were prepared in the pellet form. Details of the sample preparation and ICP OES mea surements can be found in Ref. [18].

\section{Results and discussion}

For the detection of copper as a trace element in the soil matrices, the $324.75 \mathrm{~nm}$ line from the $4 \mathrm{~s}^{2} \mathrm{~S}_{1 / 2} 4 \mathrm{p}^{2} \mathrm{P}^{0}{ }_{1 / 2}$ doublet was used. The spectra of S1 from both MA LIBS and LIBS measurements are shown in Fig. 1 respectively on the left and the right. The intensity of the line was measured, after background subtraction, by fitting the peak by a Lorentzian profile and integrating its area. In the LIBS spectrum, the $\mathrm{Cu}$ line was on a broad background structure in the spectrum. Due to the high level of noise, precise identification of each individual peak was not achieved. The Cu peaks in the MA LIBS spectrum are much more defined than those in the LIBS spectrum due to the signal and signal to noise enhancement. In Fig. 1, the integrated line inten sity of the $324.75 \mathrm{~nm} \mathrm{Cu}$ line from the MA LIBS spectrum was 14 times higher than that of the LIBS spectrum, with a 10 fold improve ment of the signal to noise ratio (SNR). Additionally, a few lines from other elements were observed, thanks to the improved SNR. Among them, the line at $328.07 \mathrm{~nm}$ was identified as the resonant $\mathrm{Ag}$ I emis sion line from the $5 s^{2} S_{1 / 2} 5 p^{2} \mathrm{P}_{3 / 2}$ transition. It should be emphasized that the concentration of silver was reported to be $23.3 \mathrm{mg} \mathrm{kg}^{-1}$ in S1 according to the ICP OES measurement and was not detected with our LIBS measurement. Consequently, MA LIBS offered in this case better performances than LIBS for the detection of these specific trace elements. It has to be noted that each LIBS experiment has its own performance depending on the experimental conditions and consequently these values comparing MA LIBS to LIBS are not to be considered absolute ones.

The calibration curves for copper are plotted in Fig. 2 for both LIBS (circles) and MA LIBS (squares). The data for each concentration
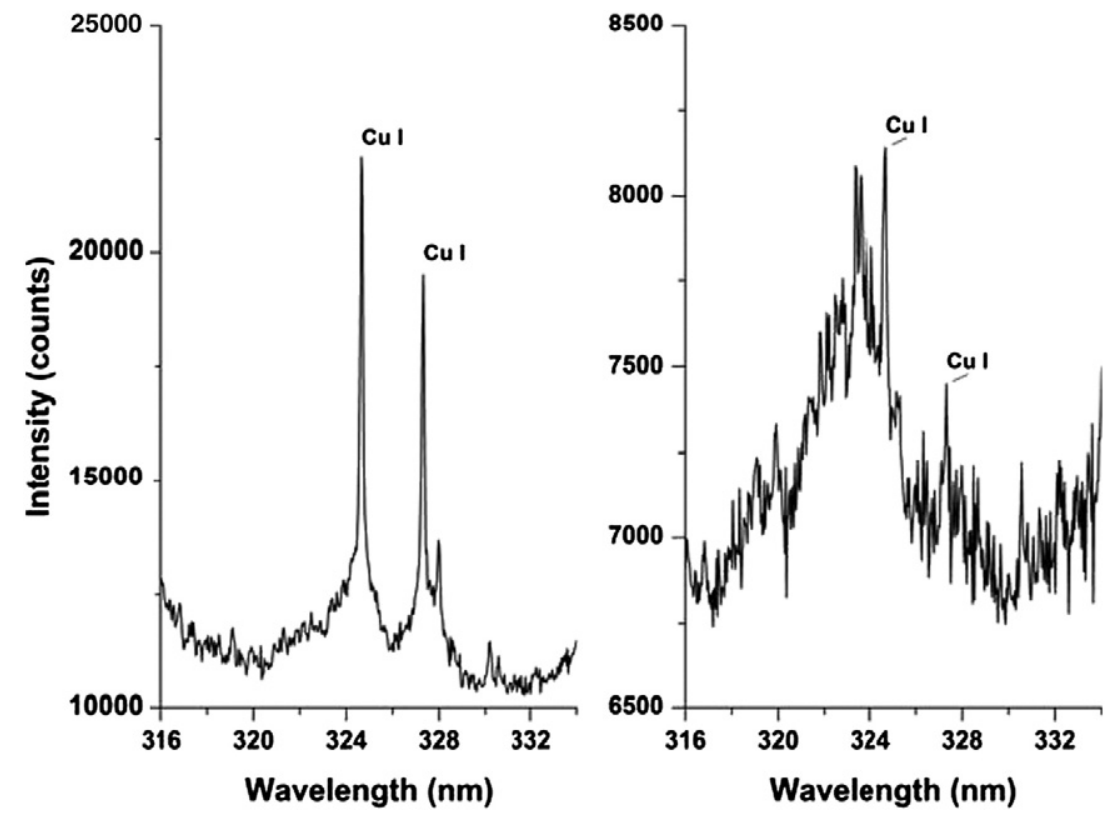

Fig. 1. Spectra of the soil sample S1 containing $1232 \mathrm{mg} \mathrm{kg}^{1}$ of Cu with MA-LIBS (left) and LIBS (right). 


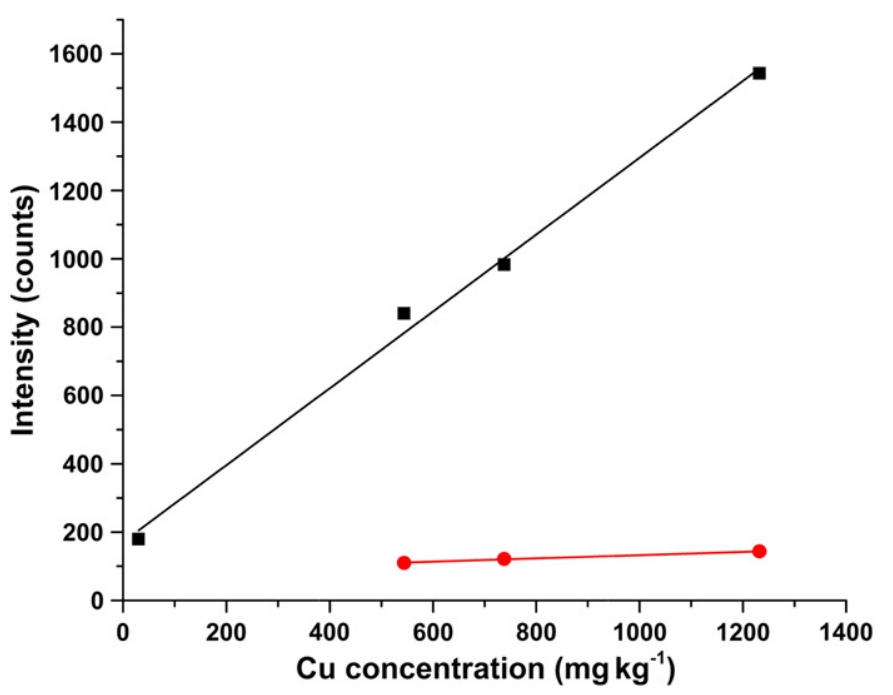

Fig. 2. Calibration curves of $\mathrm{Cu}$ for MA-LIBS (black squares) and the traditional LIBS (red circles).

consisted of five single spectra acquired at five different locations on the pellet. The mean values of the intensities were linearly correlated with the concentration of copper. The fitting results are listed in Table 2. In the case of our LIBS experiment, the sensitivity was 0.048 counts/ $\mathrm{mg} \mathrm{kg}{ }^{-1}$, while in MA LIBS, it increased to 1.12 counts $/ \mathrm{mg} \mathrm{kg}^{-1}$, which represents a 23 fold increase. The improvement of the sensitivity is by definition beneficial for an analytical method since it is one of the most important factors for discriminating between two close values of concentration. MA LIBS can thus potentially offer advantages over LIBS in deciding if a soil sample has a concentration of a given pollutant below or above a fixed threshold.

Due to intrinsic large sample inhomogeneity of the soil samples, signal fluctuations (in the range of several tens of percent) were ob served from one spot to another, for both LIBS and MA LIBS data. Such signal fluctuation is not specific to LIBS or MA LIBS but is com mon for any micro analysis method on inhomogeneous samples. In deed, even if the soil samples were prepared and homogenized as much as possible, they are still heterogeneous at the scale of the laser beam size and the observed variations are really related to local composition of the samples. Without going deeper in this dis cussion of sampling, one can understand that in this case of heteroge neous sample, the variance from point to point has no statistical meaning and that only the average value is representative of the mac roscopic sample. This is why error bars are not displayed in Fig. 2. Nevertheless, a second set of measurements was performed in this study to confirm the reproducibility of the previous result. Similar fluctuations due to the sample heterogeneity were observed, but again, the mean values of the intensity obtained for each concentra tion were linearly correlated with the concentrations (Table 2). The experimental points (average values) obtained during this second ex periment were overlapped with the previous ones and consequently not displayed in Fig. 2 for clarity. Sensitivity improved by $20 \times$ for the second set of data, which is comparable to the $23 \times$ obtained with the first set. This confirms that, despite of the large hetero geneity of the soil samples, not discussed here, the results about the

Table 2

Summary of the fitting results for two sets of experiments.

\begin{tabular}{llllll}
\hline & \multicolumn{2}{l}{ Experiment 1} & & & \multicolumn{2}{l}{ Experiment 2 } \\
\cline { 2 - 3 } \cline { 6 - 6 } & Slope & $\mathrm{R}^{2}$ & & Slope & $\mathrm{R}^{2}$ \\
\hline LIBS & 0.048 & 0.99232 & & 0.06 & 0.99872 \\
MA-LIBS & 1.125 & 0.99296 & & 1.221 & 0.99804 \\
\hline
\end{tabular}

sensitivity enhancement by MA LIBS were found to be reproducible, based on the analysis of the mean values.

In addition to the enhancement of the sensitivity, MA LIBS ex tended the range of analysis for copper, for the experimental condi tions reported here. The calibration curve built with our LIBS system covered the range from 544 to $1232 \mathrm{mg} \mathrm{kg}^{-1}$, while MA LIBS extended this range down to $30 \mathrm{mg} \mathrm{kg}^{-1}$. For the same series of soil samples, the lowest detected copper concentration reported in Ref. [18] was $80 \mathrm{mg} \mathrm{kg}^{-1}$ using another typical LIBS setup. Moreover, under our ex perimental conditions, silver has been detected only by MA LIBS, which makes this technique very promising for the detection of trace elements in soil.

\section{Conclusion}

In this paper, calibration curves of copper in soil samples were built by both LIBS and Microwave Assisted Laser Induced Breakdown Spectroscopy (MA LIBS). The MA LIBS signal for copper at $324.75 \mathrm{~nm}$ in soil samples was found to be linearly correlated to the concentration. A comparison with our LIBS data was conducted and an enhancement of sensitivity of more than 20 times was observed with MA LIBS. This improvement of sensitivity could have a significant positive impact on the monitoring of soil samples. Indeed, the ability of sorting soil samples based on their concentration of a pollutant with respect to a given threshold value could be highly enhanced. As a consequence, quick decision could potentially be taken with a higher level of confidence by MA LIBS than LIBS. However, this promising result will hold only if the signal fluctuations with MA LIBS are in the same order of magnitude as the one observed with LIBS. Future work should consequently be focused on the study of the precision in both LIBS and MA LIBS.

In addition, for soil samples, concentrations as low as $30 \mathrm{mg} \mathrm{kg}^{-1}$ of $\mathrm{Cu}$ and $23.3 \mathrm{mg} \mathrm{kg}^{-1}$ of Ag were detected by MA LIBS while not by LIBS, under the experimental condition reported here. Consequently, MA LIBS can potentially give access to spectral lines not detected by LIBS, which can be one of the major ways for detecting trace ele ments. Future work should address this important topic of improving the detection of trace elements with MA LIBS.

\section{Acknowledgment}

The authors acknowledge the following funding sources: the US Army Research Office (Contract W911NF0610446 "Ultrafast Laser Interaction Processes for LIBS and other Sensing Technologies"), the 20112012 Fulbright Scholar Program for the visit of Pr. Bruno Bousquet and the State of Florida.

\section{References}

[1] H.E. Allen, C.P. Huang, G.W. Bailey, A.R. Bowers, Metal Speciation and Contamination of Soil, Lewis Publishers, 1995.

[2] G.S. Senesil, G. Baldassarre, N. Senesi, B. Radina, Trace element inputs into soils by anthropogenic activities and implications for human health, Chemosphere 39 (1999) 343-377.

[3] A.J. Zimmerman, D.C. Weindorf, Heavy metal and trace metal analysis in soil by sequential extraction: a review of procedures, Int. J. Anal. Chem. (2010) 1-7.

[4] T. Ratuzny, Z. Gong, B.M. Wilke, Total concentrations and speciation of heavy metals in soils of the Shenyang Zhangshi Irrigation Area, China, Environ. Monit. Assess. 156 (2009) 171-180.

[5] G.C. Fang, C.N. Chang, Y.S. Wu, P.P. Fu, D.C. Yang, C.C. Chu, Characterization of chemical species in PM2. 5 and PM10 aerosols in suburban and rural sites of central Taiwan, Sci. Total. Environ. 234 (1999) 203-212.

[6] P. Gunkel, E. Roth, B. Fabre, Copper distribution in chemical soil fractions and relationships with maize crop yield, Environ. Chem. Lett. 1 (2003) 92-97.

[7] J. Fernandes, F. Henriques, Biochemical, physiological, and structural effects of excess copper in plants, Bot. Rev. 57 (1991) 246-273.

[8] B.R. Stern, M. Solioz, D. Krewski, P. Aggett, T.C. Aw, S. Baker, K. Crump, M. Dourson, L. Haber, R. Hertzberg, C. Keen, B. Meek, L. Rudenko, R. Schoeny, W. Slob, T. Starr, Copper and human health: biochemistry, genetics, and strategies for modeling dose-response relationships, J. Toxicol. Environ. Health, Part B 10 (2007) 157-222.

[9] Ecological Soil Screening Level Guidance, EPA, 2000. 
[10] A.W. Miziolek, V. Palleschi, I. Schechter, Laser-induced Breakdown Spectroscopy (LIBS): Fundamentals and Applications, Cambridge University Press, 2006.

[11] D.A. Cremers, L.J. Radziemski, Handbook of Laser-induced Breakdown Spectroscopy, John Wiley \& Sons, Ltd., 2006.

[12] J.D. Winefordner, I.B. Gornushkin, T. Correll, E. Gibb, B.W. Smith, N. Omenetto, Comparing several atomic spectrometric methods to the super stars: special emphasis on laser induced breakdown spectrometry, LIBS, a future super star, J. Anal. At. Spectrom. 19 (2004) 1061-1083.

[13] C. Lopez-Moreno, S. Palanco, J. Laserna, Remote laser-induced plasma spectrometry for elemental analysis of samples of environmental interest, J. Anal. At. Spectrom. 19 (2004) 1479-1484.

[14] G.S. Senesi, M. Dell'Aglio, R. Gaudiuso, A. De Giacomo, C. Zaccone, O. De Pascale, T.M. Miano, M. Capitelli, Heavy metal concentrations in soils as determined by laser-induced breakdown spectroscopy (LIBS), with special emphasis on chromium, Environ. Res. 109 (2009) 413-420.

[15] C. Xie, J. Lu, P. Li, J. Li, Z. Lin, Correction and analysis of lead content in soil by laser-induced breakdown spectroscopy, Chin. Opt. Lett. 7 (2009) 545-548.

[16] M.J.C. Pontes, J. Cortez, R.K.H. Galvão, C. Pasquini, M.C.U. Araújo, R.M. Coelho, M.K. Chiba, M.F. de Abreu, B.E. Madari, Classification of Brazilian soils by using LIBS and variable selection in the wavelet domain, Anal. Chim. Acta 642 (2009) 12-18.
[17] B. Bousquet, J. Sirven, L. Canioni, Towards quantitative laser-induced breakdown spectroscopy analysis of soil samples, Spectrochim. Acta Part B 62 (2007) 1582-1589.

[18] A. Ismaël, B. Bousquet, K. Michel-Le Pierrès, G. Travaillé, L. Canioni, S. Roy, In situ semi-quantitative analysis of polluted soils by laser-induced breakdown spectroscopy (LIBS), Appl. Spectrosc. 65 (2011) 467-473.

[19] IUPAC, IUPAC Gold Book, cited 2012; Available from, http://goldbook.iupac.org/ S05606.html 2006

[20] D.A. Skoog, F.J. Holler, S.R. Crouch, Principles of Instrumental Analysis, Brooks/Cole, Cengage Learning, 2007.

[21] M.E. Essington, G.V. Melnichenko, M.A. Stewart, R.A. Hull, Soil metals analysis using laser-induced breakdown spectroscopy (LIBS), Soil Sci. Soc. Am. J. 73 (2009) 1469.

[22] Y. Liu, M. Baudelet, M. Richardson, Elemental analysis by microwave-assisted laser-induced breakdown spectroscopy: evaluation on ceramics, J. Anal. At. Spectrom. 25 (2010) 1316-1323.

[23] Y. Ikeda, A. Moon, M. Kaneko, Development of microwave-enhanced sparkinduced breakdown spectroscopy, Appl. Opt. 49 (2010) 95-100.

[24] B. Kearton, Y. Mattley, Laser-induced breakdown spectroscopy: sparking new applications, Nat. Photonics 2 (2008) 537-540. 